\section{Serologically Diagnosed Toxocariasis with Hemo- phagocytic Syndrome in a Patient with Primary Biliary Cirrhosis}

\author{
Tatsuichi Ahn ${ }^{1}$, Noriyuki Houki ${ }^{1}$, Yasushi Ohkura ${ }^{1}$, \\ Kazuhiro Masui ${ }^{1}$, Hiroshi Fukui ${ }^{2}$, Keiji Shimada ${ }^{3}$, \\ Hiroshi Yamasaki ${ }^{4}$, Fukumi Nakamura-Uchiyama ${ }^{5}$ and \\ Masahide Yoshikawa ${ }^{6}$
}

Key words: toxocariasis, Toxocara canis, hemophagocytic syndrome, visceral larva migrans

\section{(DOI: 10.2169/internalmedicine.45.1485)}

Hemophagocytic syndrome (HPS) is a clinicopathological condition characterized by activation of macrophages or histiocytes with prominent hemophagocytosis in bone marrow and other reticuloendothelial systems (1). The clinical features include high fever, hepatosplenomegaly, lymphadenopathy, skin rash, coagulopathy, and cytopenia. Herein, we report a case of serologically diagnosed toxocariasis with manifestations similar to HPS lacking cytopenia. Although larvae were not found in the visceral organs by autopsy, visceral larva migrans (VLM) was strongly suspected based on the distinctly positive results in enzyme-linked immunosorbent assays (ELISAs) for Toxocara (T.) canis.

A 51-year-old man was diagnosed with primary biliary cirrhosis (PBC) (Scheur stage III) in 1995 based on symptoms (itching), biochemical data, and liver histology findings. The father of this patient was also diagnosed with asymptomatic PBC, and both cases were previously reported as $\mathrm{PBC}$ in a father and son (2). Since the time of that first study, the patient had been treated with ursodeoxycholic acid alone. Although endoscopic treatment was required for ruptures of esophageal varices, the patient remained in a stable compensated condition until the beginning of January 2005, when he developed a skin rash, fever, severe fatigue, and deteriorated liver function with ascites retention. At that time, laboratory data revealed prominent leukocytosis (WBC $25 \times 10^{3} / \mu \mathrm{l}, \mathrm{Hb} 12.7 \mathrm{~g} / \mathrm{dl}$, Plt $\left.12 \times 10^{4} / \mu \mathrm{l}\right)$ with marked eosinophilia $(>80 \%)$ and elevated $\operatorname{IgE}(2100 \mathrm{U} / \mathrm{ml}$, normal 0 less than $100 \mathrm{U} / \mathrm{ml}$ ), while the ascites was found to contain a considerable number of eosinophils. A thoracic-abdominal
CT examination showed hepatosplenomegaly and lymphadenopathy in the para-tracheal and para-aortic areas. Bone marrow aspiration demonstrated an increase in eosinophils, but no malignant cells. Following serological screening for parasitoses using a multiple dot ELISA, toxocariasis was suspected, and a microplate ELISA assay against $T$. canis excretory-secretory antigens revealed a markedly high antibody titer in 1:900 diluted serum [optical density (O.D.)> 0.9, threshold O.D. 0.2]. Seropositivity against T. canis was further confirmed using a microplate ELISA with a recombinant $T$. canis antigen (3), which is highly specific for toxocariasis. A serum sample taken prior to development of the manifested symptoms and eosinophilia was unavailable, and the route of T. canis infection such as daily contact with dogs was not determined. Based on the marked seropositivity against $T$. canis shown in 3 different ELISAs, we made a diagnosis of infection with $T$. canis.

Prior to the introduction of antihelmintic therapy, the patient died of multiple complications, including pneumonia and disseminated intravascular coagulation, in February 2005. Autopsy results confirmed lymphadenopathy in the mediastinum and peritoneal cavity. Further, a histological examination showed hemophagocytic foamy cells in the lymph nodes (Fig. 1A, B) and bone marrow (Fig. 1C), though no neoplastic cells were observed. Erythrophagocytosis was also observed in Kupffer cells in the liver (Fig. 1D). Histological evidence of VLM such as the presence of larvae or eosinophilic granulomas could not be demonstrated in the visceral organs.

Toxocariasis presents various manifestations including multiple hepatic nodules, eosinophilic pneumonia, systemic vasculitis, and rheumatic arthritis-like symptoms. However, there is no known description regarding the development of HPS in toxocariasis. HPS is known to be associated with infections, mostly viral, as well as malignancy and autoimmune diseases. Although no specific viral infection, including cytomegalovirus and Epstein-Barr virus, or malignant cells were demonstrated in the present case, the possible role of underlying PBC could not be eliminated in the development of the HPS-like condition with eosinophilia in the present patient. Finkielman et al. (4) reported a case of HPS that developed in a patient with systemic lupus erythematosus complicated with strongyloidiasis. Since helminthiasis is known to affect the host immune system by activating T-helper 2 cell responses and macrophages (5), HPS might

\footnotetext{
${ }^{1}$ Department of Internal Medicine, Kokuho Central Hospital, Tawaramoto, ${ }^{2}$ Department of Gastroenterology and Hepatology, Nara Medical University, Kashihara, ${ }^{3}$ Department of Pathology, Nara Medical University, Kashihara, ${ }^{4}$ Department of Parasitology, Asahikawa Medical College, Asahikawa, ${ }^{5}$ Department of Infectious Diseases, Faculty of Medicine, University of Miyazaki, Kiyotake and ${ }^{6}$ Department of Parasitology, Nara Medical University, Kashihara

Received for publication July 1, 2005; Accepted for publication November 6, 2005

Reprint requests should be addressed to Masahide Yoshikawa, the Department of Parasitology, Nara Medical University, 840 Shijo-cho, Kashihara, Nara 634-8521
} 

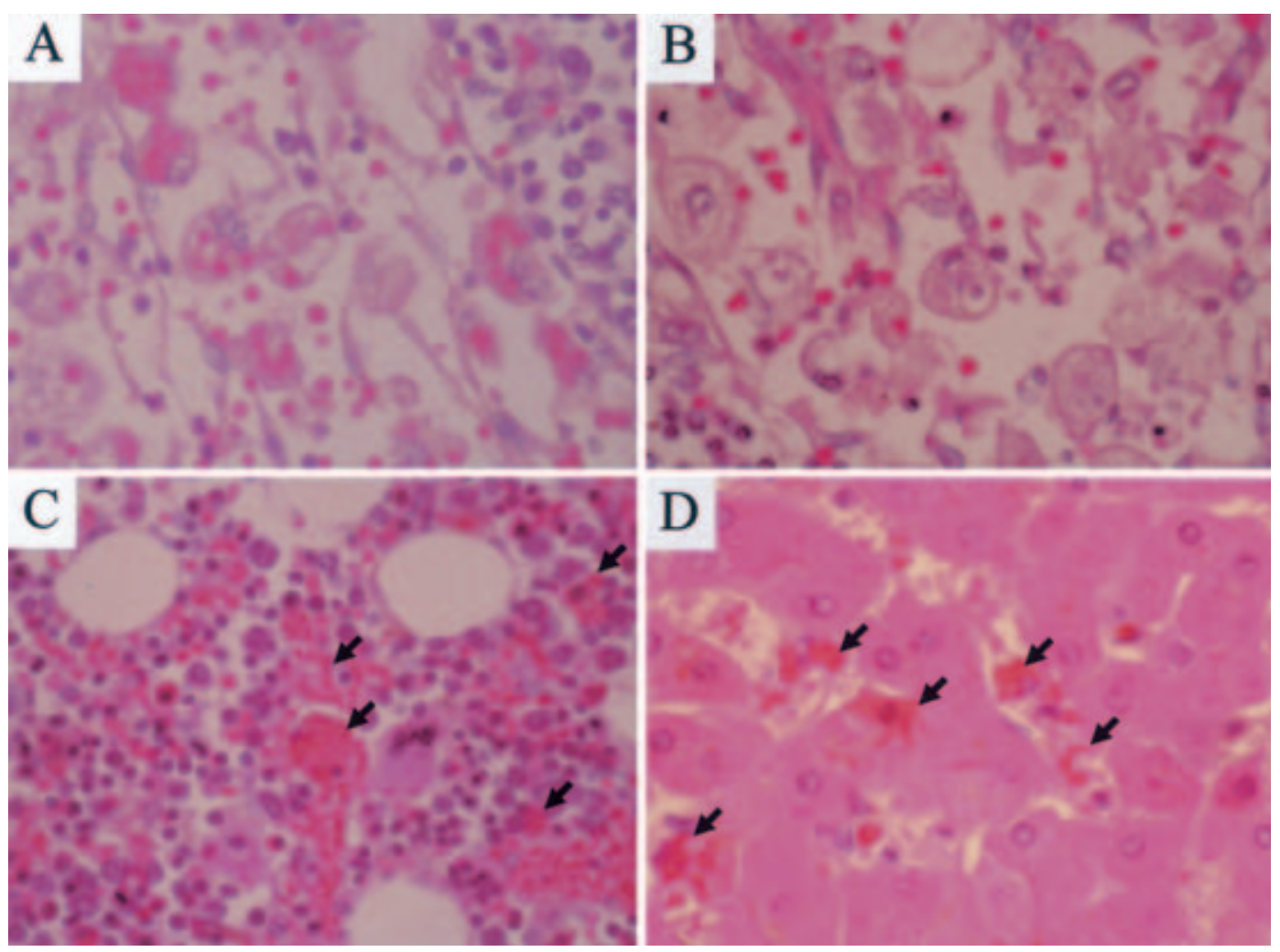

Figure 1. Microsopic examination of the para-tracheal lymphnode (A, B), bone marrow (C) and liver $(D)($ HE stain $\times$ 200). Foamy cells with hemophagocytosis were prominently present in the lymph node (A, B). They were also found in the bone marrow (C, arrow). Kupffer cells phagocyting erythrocytes in the liver were found in D (arrows).

result from a combination of autoimmune diseases and helminthiasis.

\section{References}

1. Kumakura S. Hemophagocytic syndrome. Intern Med 44: 278280, 2005.

2. Shiroi A, Yoshikawa M, Kinoshita K, et al. Primary biliary cirrhosis in a son and his father. Acta Hepatologica Japonica 39: 335339, 1998 (in Japanese).

3. Yamasaki H, Araki K, Lim PK, et al. Development of a highly specific recombinant Toxocara canis second-stage larva excretorysecretory antigen for immunodiagnosis of human toxocariasis. $\mathrm{J}$
Clin Microbiol 38: 1409-1413, 2000.

4. Finkielman JD, Grinberg AR, Paz LA, et al. Case report: reactive hemophagocytic syndrome associated with disseminated strongyloidiasis. Am J Med Sci 312: 37-39, 1996.

5. Maizels RM, Balic A, Gomez-Escobar N, Nair M, Taylor MD, Allen JE. Helminth parasites-masters of regulation. Immunol Rev 201: 89-116, 2004.

(C) 2006 The Japanese Society of Internal Medicine http://www.naika.or.jp/imindex.html 